\title{
Sandplay Therapy Performed by Telepsychotherapy: Going Beyond the Limits of Face-to-Face Psychotherapy in the COVID-19 Pandemic
}

\author{
정 병 호* \\ Jung, Byungho
}

\begin{abstract}
$<$ Abstract $>$
As COVID-19 spreads internationally for an extended period of time, millions of people around the world are suffering from psychological symptoms such as anxiety, depression, PTSD, and loss, and the role of psychotherapy is growing more than ever. However, in the current situation where anxiety about infection is widespread, the form of face-to-face psychotherapy has become another factor that induces infection anxiety. The limitation of this existing psychotherapy leads us to think of alternatives that can reflect the rapidly changing clinical situation in different ways during the ongoing coronavirus period. Telepsychotherapy is a form of psychotherapy that has been practiced for distant clients for a long time and can be a safe alternative psychotherapy method for both clients and analysts in the pandemic era. Although some analytic psychotherapists have negative views on telepsychotherapy, the change in the psychological treatment environment caused by COVID-19 leads to a new perspective on telepsychotherapy. The subjects of anxiety, depression, and death that people are experiencing because of the coronavirus pandemic come to us as archetypal shadow. The symbols unfolded in sandplay therapy direct our gaze to the inner world of human beings during this pandemic period and make us look at the unintegrated archetypal figure in the deep conscious. This paper aims to examine the therapeutic meaning and value of sandplay therapy that is performed according to the method of telepsychotherapy by analyzing the case of changed clinical situation due to the pandemic.
\end{abstract}

Keywords : COVID-19, Archetypal Shadow, Telepsychotherapy, Sandplay Therapy

* Byungho Jung, Professor, Department of Family Counseling, Healing \& Counseling Graduate University (play-therapy@hcg.ac.kr) 
Journal of Symbols \& Sandplay Therapy, Vol.12 No.1.

\section{I . Introduction}

COVID-19, which started in Wuhan, China at the end of December 2019, is caused by a novel coronavirus, SARS-CoV-2, and can cause potentially infectious pneumonia (Xin, et al., 2020). Accordingly, on January 30, 2020, the World Health Organization announced COVID-19 a public health crisis that should be of international interest and called for efforts to prevent the infectious disease. According to the WHO, as of February 2021, COVID-19 has spread to 233 countries and regions worldwide, with 106,556,206 people infected, and 2,333,446 deaths from this fatal epidemic (WHO, 2021). The infection of COVID-19 is still ongoing, and psychotherapy experts have been trying to help those who suffer psychologically from it.

COVID-19 is an international public health crisis, where people struggle with the limits of their psychological capacity to cope with this ongoing turmoil, causing negative psychological consequences for both infected and healthy individuals (Yildirim, et al., 2020). This epidemic is also rapidly affecting people's health, as well as their social, educational, and economic wellbeing, as it affects almost every aspect of life. In addition, blockade measures to prevent contagion are causing overall social problems such as social alienation and job loss. Social isolation and financial problems lead to negative psychological symptoms (Dutra \& Rocha, 2020). The coronavirus is affecting the entire economy, and it appears that people experience more anxiety and depression when they do not have a job (Shah et al., 2020). COVID-19 has increased uncertainty about the future, and is increasing serious post-traumatic stress symptoms (Shigemoto, 2021).

Due to COVID-19, countries are taking measures to create distance within society, by closing schools, working from home, and banning travel. Counseling centers are also avoiding face-to-face counseling due to concerns about infection. Such rapid social isolation is bringing about a change in the perceptions of therapists and clients who were used to face-to-face psychotherapy (Johnson et al., 2020). In the age of coronavirus where social distancing is mandatory, innovative methods to overcome the barriers of face-to-face psychotherapy are needed, and one of the alternatives is telepsychotherapy (Watts et al., 2020). This approach not only protects psychotherapists and clients from the risk of infection, but also provides a new 
therapeutic opportunity in the sense of communicating in the client's natural field of life (Douglas et al., 2020). In the pandemic era, telepsychotherapy can be one of the key therapeutic approaches, and has been proven that it can be well provided to clients in need of psychotherapy (Perrin et al., 2020).

Analytical psychotherapists have had a negative view of telepsychotherapy due to distorted analytic frameworks and concerns about relational dynamics. However, in the era of the COVID-19 pandemic, technological methods such as telepsychotherapy have come to mind, and people who use it for psychological treatment have arisen. According to an empirical study on telepsychotherapy by analytic therapists (Bekes et al.,, 2020), despite technical and relational difficulties, therapists said that they felt a genuine connection with clients through telepsychotherapy, as strong as face-to-face psychotherapy. Some therapists reported feeling low-level connections with their clients, and a few reported that they were unsure about using the new technology. Overall, in the pandemic era of uncertain and rapid change, telepsychotherapy is attracting attention as a way to provide high-quality psychotherapy for clients.

Analytical psychology interpretation differs from clinical psychological and cognitive behavioral perspectives that look at the overall socioeconomic and psychological problems such as confusion, anxiety, depression, and fear in the pandemic era caused by COVID-19. Analytical psychology does not pay attention to external phenomena, but rather looks at the crisis of the pandemic era through insight into the deep spiritual world within humans. The pandemic that is happening around the world is not individual, but collective, and archetypal shadow is falling equally on everyone. By accepting the fear and anxiety of dark death in the pandemic era as a revelation, we are in a position to face and unite the archetypal shadow that we were not familiar with (Stein, 2020). This insight of analytic psychology into the sudden, unwanted, and unexpected pandemic era gives us an opportunity to listen, look, and understand the deep inner world. Many people look for problems to be solved in the outside world, but the perspective of analytical psychology directs our gaze to deep inside the human mind and suggests the direction we should go in the confusion of a pandemic era. This thesis aims to analyze the client's inner world and examine the therapeutic implications through reviewing a sandplay case that was 
Journal of Symbols \& Sandplay Therapy, Vol.12 No.1.

performed by telepsychotherapy from July to December 2020, when COVID-19 spread exponentially. Sandplay therapy shows us the world of infinite symbolism and gives the limited ego an opportunity to see and experience life from a new perspective. At the point where our consciousness cannot reach, sandplay therapy symbolically shows us the mysterious and wonderful inner world of human beings.

\section{Psychological symptoms caused by COVID-19}

The long coronavirus era around the world has had a great impact on mental health as well as daily life. Above all, in an age of pandemic, which causes uncertainty, people experience various mental problems such as depression, anxiety, and stress. People are under the complex stress of experiencing loss and long periods of exposure to information that causes anxiety (Gruber et al., 2020). During this period of crisis, people experience isolation, which leads to many negative psychological issues (Henssleret et al., 2020) such as increasing domestic violence (Buttel et al., 2021) and alcohol problems (Wardell et al., 2021). Because of these various negative emotions and psychological problems, people are secondarily suffering from a potential posttraumatic stress disorder (Zvolensky et al., 2020). In particular, people who are self-critical and dependent seem to feel more and more negative emotional reactions and loneliness, and struggle through difficult times (Besser et al., 2020).

Stressful events cause anxiety and depression, and COVID-19 has inflicted psychological damage on people, causing anxiety and depression (Kujawa et al., 2020). The main strategy to cope with the spread of the coronavirus epidemic is quarantine, which is a safety device to prevent infection, but it also brings disconnection from external factors that can reduce stress (Gruber et al., 2020). People who have experienced quarantine are experiencing more problems such as depression, anxiety, stress-related problems, and anger than those who have not experienced isolation (Henssleret et al., 2020). Especially those who have been diagnosed with COVID-19, or individuals who know a person who died due to the disease, appear to experience higher levels of stress, very poor mental health, and dysfunction (Gallagher et al., 
2020).

Depression and anxiety symptoms caused by the coronavirus pandemic are appearing worldwide. People in Korea are suffering from 'corona blues', or depression and lethargy due to the persisting coronavirus pandemic (Shin \& Lee, 2020), and people are also affected by trauma related to anxiety and the coronavirus in Japan (Shigemura \& Kurosawa, 2020). According to a meta-analysis conducted in China, where the coronavirus began, the combined prevalence of anxiety is $25 \%$ and depression is $28 \%$, and it is reported that health care professionals dealing with these issues are experiencing psychological stress (Ren et al., 2020). This increased negative emotional experience of depression and anxiety appears to be associated with increased suicide risk. According to a coronavirus-related meta-analysis conducted in the United States, a study found that hopelessness and worthlessness increased from 2018 to 2020, which increased the risk of suicide and intensified serious mental distress (Twenge \& Joiner, 2020).

In the coronavirus era, as social distancing becomes commonplace, people are experiencing many mental problems within their families because more social functions have to be handled at home. With the closure of schools, more women are feeling depressed and anxious, as more tasks are imposed on women who have to spend most of the day on the responsibility of caring for their children. Children who are protected by women at home do not have a relatively negative psychological experience. Therefore, parents sharing the responsibility of raising children together becomes an important factor in protecting the mental health of the family (Yue et al., 2020). Long-term social distancing also leads to an increase in domestic violence, which is believed to be caused by weakened resilience and increased stress. The problem of external violence across society can be reduced through isolation, but the increasing intimate partner violence in the home suggests that families at risk need psychological help (Buttel et al., 2021).

People cope with the negative emotions and isolation problems caused by the long-term pandemic in various ways, and some of them solve those emotions through substance abuse. People who used alcohol to cope with depressive symptoms and social isolation problems consumed more alcohol, which led to more alcohol-related problems (Wardell et al., 2020). People who smoke as a way to relieve stress are more likely to receive treatment in an intensive care unit if they become infected with coronavirus, and they are susceptible to severe 
Journal of Symbols \& Sandplay Therapy, Vol.12 No.1.

infection. The incident of people who solve the painful emotions caused by coronavirus through cannabis is also increasing, though cannabis harms the lungs of users, exacerbating coronavirus symptoms (Zvolensky et al., 2020).

\section{Telepsychotherapy}

The coronavirus pandemic can cause people to experience constant fear, social isolation, economic stress, loss of resources, and the death of a family member or close friend. In the prolonged pandemic era, people experience extreme psychological pain, increasing the need for psychological treatment more than ever. But the reality is that it is difficult to provide face-to-face psychotherapy due to social isolation and the risk of infection (Johnson et al., 2020). At a time when the risk of infection due to coronavirus is widespread, the need for telepsychotherapy is emerging more strongly than ever, in particular for clients who need psychological support beyond distance limits (Perrin et al., 2020). Telepsychotherapy provides psychotherapy through video conferences, which are a creative answer to the question of how to provide psychotherapy in the age of pandemic, as psychotherapists can simultaneously understand and observe the verbal and nonverbal expressions of the client (Inchausti et al., 2020).

The method of telepsychotherapy through video conferences in which the client and psychotherapist face each other helps to develop a therapeutic alliance appropriately for clients suffering from anxiety (Watt et al., 2020). Telepsychotherapy reduces the risk of infections that people fear, and enables continuous psychotherapy for both clients and psychotherapists in their own safe space (Rosen \& Glassman, 2020). There is a skepticism about the formation of therapeutic alliance through telepsychotherapy, but recent studies have shown that it provides an opportunity to improve treatment alliance and empathy (Douglas et al., 2020). It is demonstrated that psychological treatment can be safely provided to clients (Madigan et al., 2020). Social isolation, recession, and increase in unemployment due to prolonged coronavirus are associated with depression, anxiety, and suicide risk, and psychological intervention through distance psychotherapy may be effective for clients suffering from such psychological distress 
(Jobes, Crumlish, \& Evans, 2020).

Telepsychotherapy has been used since before the coronavirus, but many psychotherapists have doubted the use of it for psychotherapy (Pierce et al., 2021). However, due to the changes in the clinical environment in the pandemic era, more people have become interested in telepsychotherapy. The biggest advantage of telepsychotherapy is that it is possible to meet clients beyond the limits of isolation and closure, which are characteristic of the pandemic era. Despite these advantages of telepsychotherapy for meeting the needs of the coronavirus era, psychotherapists are hesitant to fuse a new method called telepsychotherapy with the way of providing psychotherapy. Their reluctance may be due to a lack of training or experience in using new skills in psychotherapy, rather than the rejection of performing telepsychotherapy. Psychotherapists have rarely been trained in remote psychotherapy and tend to be unaware of how to explain to their clients a new way of distant psychotherapy that is different from traditional psychotherapy (Daele et al., 2020).

Although there are several advantages of telepsychotherapy, its limitations are clear. The process of establishing a trust relationship is more difficult than in face-to-face psychotherapy, so some clients may wait to receive face-to-face psychotherapy (Bennett, Sever, \& Yanouri, 2020). Also, if clients do not have the Internet or cannot understand the technical aspects related to the Internet, they cannot receive it. Another difficulty in telepsychotherapy, and this can be a serious problem, occurs when the client is living with family members in a small space and there is no safe place that can provide adequate confidentiality (Madigan et al., 2020).

Despite these limitations of remote psychotherapy, it has been reported that more psychotherapists have become interested in telepsychotherapy and have used it for psychotherapy in a new environment since the start of the coronavirus pandemic (Pierce et al., 2021). The era of the coronavirus pandemic is demanding new changes in all areas and is the biggest challenge in providing psychotherapy (Inchausti et al., 2020). Providing telepsychotherapy in the mid- to long-term, beyond the limits of face-to-face psychotherapy, must be one way to safely provide psychotherapy in the current situation where social isolation is enforced worldwide (Daele et al., 2020). Anxiety accompanies the various negative emotions of the unpredictable COVID-19 pandemic. However, fortunately, at this time when depression hits the world, we can provide 
Journal of Symbols \& Sandplay Therapy, Vol.12 No.1.

psychotherapy to clients using telepsychotherapy (Rosen, Glassman, \& Morland, 2020).

\section{Understanding the COVID-19 pandemic in analytical psychology}

There has been a variety of approaches and explanations for the understanding of the COVID-19 pandemic, which has suddenly overwhelmed the world. Among them is the deep insight of analytic psychology regarding the pandemic's chaos and crises that understands and explains the human psyche and suffering from a different level. While most psychological approaches pay attention to the external psychological symptoms revealed by COVID-19, analytical psychology studies the various mental layers of the psyche, the unconscious, and the collective unconscious as a whole.

Stein (2020) describes the image of COVID-19 as an image related to Umbra Mundi, a world shadow, which is said to have an enormous influence on our minds. According to him, the threat of death, Umbra Mundi, is the companion and shadow of Anima Mundi, the symbol of life, the divinity of the material universe, and the spirit of the world. Hillman (1988) argues that Anima Mundi as Psyche has already existed since the beginning of the world, so the first goal of psychology is to find the logos for the psyche, and the second goal is to hear what the psyche is talking about through the world. It is said to be rediscovering the spirit world that gives life to the learning.

On the contrary, Umbra Mundi approaches us with death and fear as an archetypal shadow (Stein, 2020). Jung distinguished between personal shadows and archetypal shadows. The personal shadow is a repressed part that is not pleasing to consciousness and has a rewarding aspect to the ego. The archetypal shadow appears to us as a sudden, strange, absolute demon, differing from personal shadows, which can be like relative demons. This shadow is like a small door in front of the deep side of the mind, which is hard for anyone to know. However, if someone wants to know themselves, it is an area they have to approach, open the door, and learn. Looking at the archetypal shadow through the analysis of adult clients, it can be seen as a side of confusion and the total annihilation of the primitive ego (Moore, 1984). Shadows are a 
central and important part of Jungian psychology, and the contents of the shadows are closely related to the archetypal shadows of the collective unconscious. Above all, the contents of the shadows are autonomous and generally contain contents that individuals do not want to know (Casement, 2003).

The COVID-19 pandemic is an symbolic image of Umbra Mundi that envelops and invades our lives in confusion and darkness in a way that we cannot predict. Around the world, Umbra Mundi is threatening humanity in the form of darkness and death and is attacking our unstable world. In these terrible times of crisis, we have an opportunity for a vast consciousness change at the universal collective level. We can see the possibility of a deep change in the collective unconscious through Umbra Mundi, the shape of the archetypal shadow at this time. In the pandemic era, many people look at extroverted anxiety and fear, but it is important that we look at the inner world and the subjective world, and recognize, unite, and confront the death and anxiety of Umbra Mundi that we were not aware of (Stein, 2020).

Sandplay is a non-verbal and irrational form of therapy that reaches the profound pre-verbal stage of the mind (Weinrib, 2004). In sandplay therapy, therapists provide a protected and safe space and engage in unconscious forces and passion with the client (Bradway \& McCoard, 1997) This therapeutic space provides a psychological space where clients can meet their inner world and various archetypal symbols. In the sandbox, clients experience a time of change in which they meet the archetypal shadows and symbols of the Self, communicate with them, and integrate them. In this respect, sandplay therapy is a psychological treatment that projects the inner mind onto symbols such as sand, figures, and play imagination (Hwang, 2020).

\section{Case study}

The client reported that she was a middle-aged woman in her early 50s, working as a school counselor, and felt helplessness, lack of energy, isolation from school closures, a little depression, and anxiety due to the coronavirus pandemic. Because she also had doubt in her own role as a therapist, she was interested in receiving sandplay therapy through telepsychotherapy. After 
Journal of Symbols \& Sandplay Therapy, Vol.12 No.1.

reviewing her current psychological problems, this researcher concluded that telepsychotherapy was appropriate for her. The client was informed about confidentiality and the advantages and disadvantages of telepsychotherapy. She then consented to participate in the study. She also agreed to have telepsychotherapy once a week in the client's sandplay therapy room and discussed with this researcher possible problems related to an emergency clinical situation as well as Internet technical issues. The client has a therapy room with her own sandplay tools, and the same process was performed through video conferences as in face-to-face sandplay therapy. The client's smart phone was fixed so the analyst was able to share the client's sand play through video. After completing the sandplay session, the client took a picture with her own camera and sent it to the analyst. Sometimes the session was temporarily interrupted by people who visited the client, but overall, it was as smooth as a face-to-face sandplay therapy. The client had received a short course of psychotherapy two years ago and again received sandplay therapy from August 2020 to December 2020. In this study, the analysis was focused on sand pictures, which brought great changes to the client during several sessions.

In the fifth session, the client started playing in the sand with the theme, "I am playing." She then placed an asphalt road under the center of the sandbox, placed a car on it to the left, and fences around the road. She placed palms, bushes and trees in an array around the road, with the Statue of Liberty on the left and two eagles around it. The client carefully dug the sand for a long time to create a large puddle in the upper right corner, and then placed a well on top of it so that the spring water could be pumped up to her heart's content, but it did not work out. So she placed jewelry on the bottom of the puddle and then put the well on it again. The client placed cars on the road below the center, created a lake above the sandbox, carefully placed a shark there, and created a river so that the water stream flowed from the top to the bottom right of the box. She placed a dancing woman on the left side of the road and owls in the river above the box. She put an angel in the upper left corner of the box and said that the angel was praying for the shark to go safely out into the distant sea, and that the owls were also supporting the shark. She said that the shark was particularly cute and showed a lot of attachment to the shark. The client placed a woman by the well in the upper right and said that she had a confused mind. The client, who was not happy with the 
woman at the well, tried changing positions with the dancing woman in brilliant red at the end of the street, but said that it did not match, and placed the woman by the well again. The client talked about the excitement and feelings of freedom while looking at the dancing woman and the Statue of Liberty, and said that she felt frustrated because the river with sharks was too narrow.

As the client said that she was "playing," various unconscious symbols appeared, and the client was playing by meeting different layers of psyche. Water symbolizes the source of life and creation, death and resurrection, chaos and order, and purification and holiness (Eom, 2014). She dug a spring and built a well to pump up the water of life, as if finding inner energy from the deep unconscious. The depressed woman who pumped water from the well stands sadly, not rejoicing even though she encountered and touched the abundance of her unconscious, which symbolizes the client's weary and fragile ego. Kalff (2003) said that sandplay therapy creatively connects consciousness and unconsciousness, but the client's limited consciousness (the depressed woman) is connected to a deep layer of the unconscious (the well). The client is an introverted person who is uncomfortable and finds it difficult to express her internal feeling and thoughts. However, her unconscious world in the sandbox is dynamic and full of power. Two vehicles on the road below the center of the sandbox run towards a woman wearing flashy red and dancing passionately, with the Statue of Liberty behind her. The melancholy woman who pumps water from the well stands sadly, not rejoicing even though she encounters and touches the abundance of her unconsciousness, which symbolizes the client's weary and frail ego. The dancing woman and the Statue of Liberty are intense, dynamic, and free figures that contrast with the client's introspective figure. The client's energies are running to unify the contradictory elements (Bradway \& McCoard, 1997). The shark goes over the narrow, stuffy river and heads for the far sea, indicating that the client's deep unconscious impulse is heading for a wider area.

The client reported in subsequent sessions that she felt as if the figures in the sandbox were whispering to her. She seemed to experience becoming closer to the symbols in the sandbox by contacting the inner world and the deep unconscious world unfolding beyond the limits of her own vulnerable and anxious ego. Human unconsciousness is expressed through symbols (Hwang, 2020). The client began to learn about and integrate the potential aspects of the unconscious 
that she did not know through the time of conversation and experience with the symbols of the unconscious appearing in the sandbox.

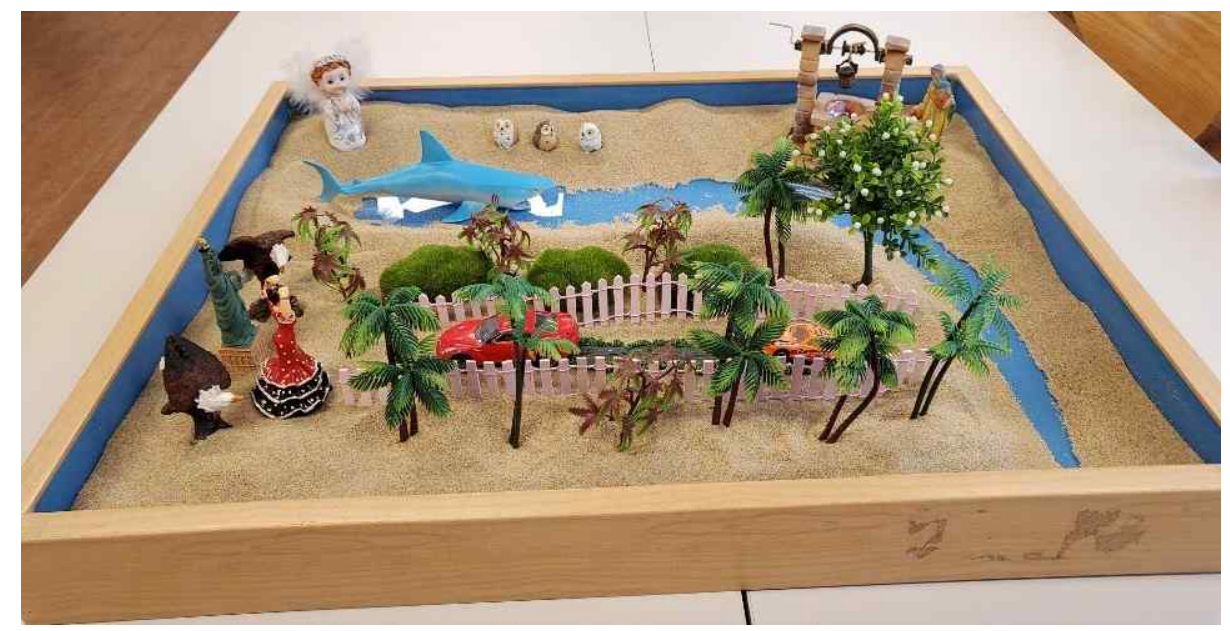

Picture 1. I am playing

In the ninth session, the client placed a tiger in the upper left corner of the sandbox first, and a palm tree in the middle of the right hand side, a lake in the middle, and a shellfish in the middle of the lake. Then she placed a fruit tree on the right side of the sandbox, placed flowers next to it, and placed a grandfather and grandmother right on top of the box. The client placed a tree behind, a Pegasus right above, and a sleeping angel in front of the grandparents. The client placed a few rocks on the left under the sandbox, jewels on them, two butterflies on a palm tree, a butterfly on a rock, and a road in the center left. Then she placed the snake right in front of the tiger. After completing the sandbox, she began to say that she was paying attention to the tiger rather than talking about a special feeling. The client said that it looked good for the tiger and cubs to be together, and the tiger mother seemed a little anxious and wanted to protect the cubs, but she seemed to be weak. The client seemed to be worried about the tiger mother and, after a while, scared about the tiger, she set up a fence to confine the tiger. The client looked at the grandparents in the sandbox while thinking about her grandparents. She said that they were scared and nagged, and talked about the various memories of her childhood at their home. The client said that due to family circumstances, she 
grew up at her grandparents' house when she was very young, but when she entered elementary school, she went back to her mother's home, but felt like she wasn't a family member.

The symbolic features of the deep unconscious appearing in the sandbox provided an opportunity to meet inner potential and energies(Kalff, 2003). The client was playing in the sand, feeling the memories of leaving home as a child and living in her grandmother's house. She also expressed the helplessness she felt in the relationship with her own children through the appearance of the tiger. However, from a deeper perspective, the client met a snake, a symbol of feminine wisdom and libido vitality (Kim, 2020) in the sandbox, and a seashell, a symbol of spiritual archetypes, and the possibility of new development(Carey, 1999), that showed that her fragile ego was experiencing new developmental possibilities. Based on these intense experiences, the client first spoke of the uncomfortable feelings she felt toward the analyst, who was mainly silent during previous sessions. She expressed feelings of discomfort by asking if the analyst was silent during the last sessions because he did not know what to say or had nothing to say. The client's challenging appearance was completely different from her usual adaptive and introverted appearance. Near the end of the session, she asked the analyst if he was angry with what she had said or if she had made any mistake. So the analyst explained to her that there was no such thing. In this session, the client looked much more stable, comfortable, and powerful (previously, there were many situations where the client was anxious, unconfident, or hesitant).

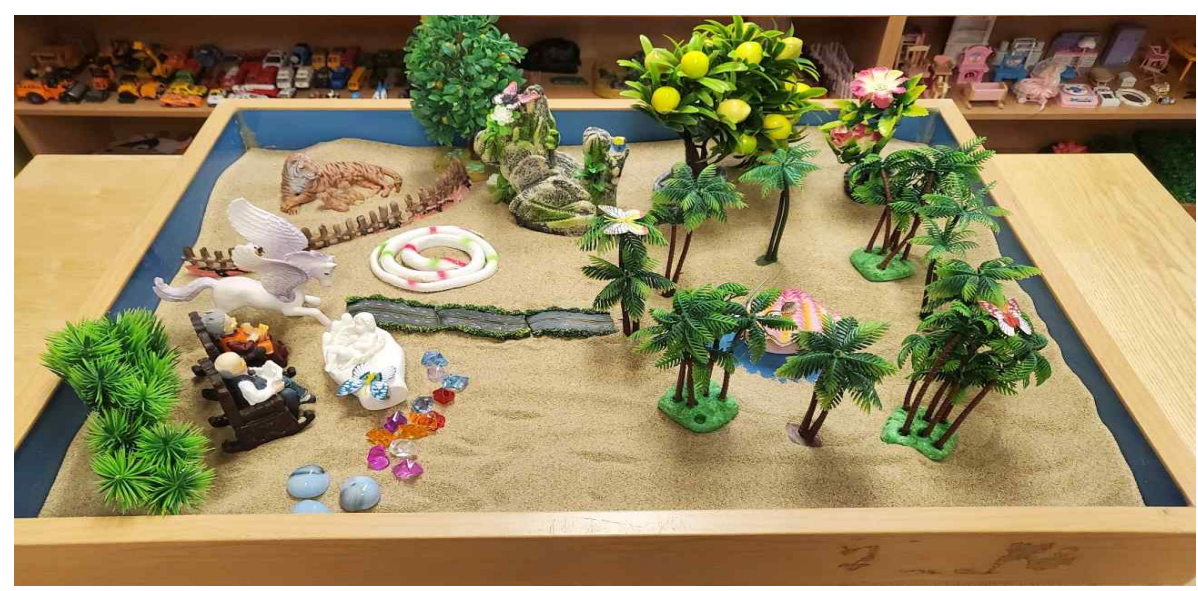

Figure 2. Beginning of change 
Journal of Symbols \& Sandplay Therapy, Vol.12 No.1.

In an analysis prior to the final session, the client struggled, saying that she had intense murderous anger toward her children. However, she was deeply impressed with the presence of a peaceful scene (a woman leisurely riding a bicycle in a central lake surrounded by a fence) that contrasts with the destructive aspects of her life, as the client sees that her sand picture said. She said she always tried to get rid of anxiety or negative feelings, but she said she was impressed by the fact that there was peace in her internal world that she had not known. The client also said she had practical experience in learning Jung and discovering safety inside, not outside.

In this session, she placed the grandmother on the left side of the sandbox, placed a table in front of her, and also placed two children and food in front of her. Then, a river was created in the center of the sandbox, bridges were placed to connect the two divided areas, and fish were placed in the water. Cats and other animals were placed behind the grandmother, and chicks hatching from eggs were placed behind them, and other birds were placed around them. The client placed a small rainbow-like bridge at the top, connecting the other two areas again, placing a tree in the lower right, a temple on it, and placing the children in front of the rainbow bridge. She placed an adult man in front of a tree on the right side of the sandbox, a goddess in front of him, and a plane on the right, saying that she wanted to go on a trip. The client said that after completing the sand painting, she thought she might be able to take

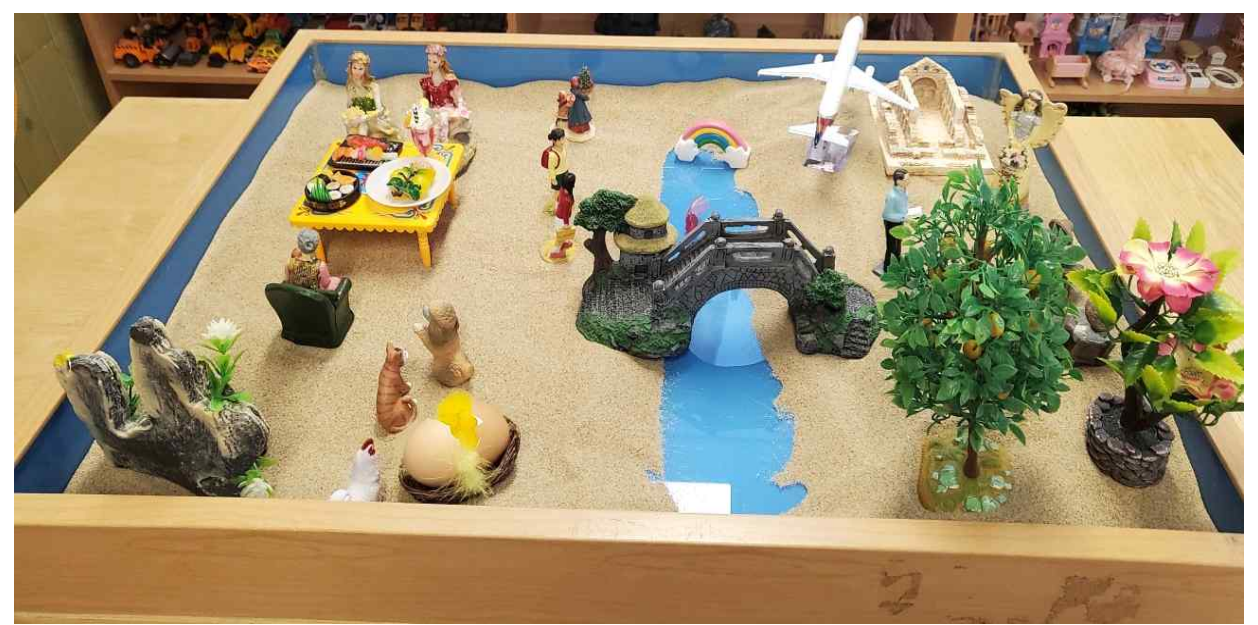

Figure 3. Communication between the two worlds 
care of herself now. She said that if she needs nutrients, she can eat food, and study if she needs to study, as seeing the rainbow bridge brings feelings of hope. The client pointed to the temple, saying that religiosity protects her, and that her grandmother seems to represent the wise part of herself.

In looking at the temple in the sandbox, which represents the sacred religious symbol, the client is communicating with her own deep religion, as well as experiencing care and expansion into a new world. Jung (1966) says that religion was the most common activity of the human mind in early human history and is a social and historical phenomenon among human psychological structures. He observed that religion is a very important part of human history and that understanding people's religiosity offers deep understanding of the inner human spirit, and that religion is an essential human experience. The client is encountering the deep religiosity of her inner being symbolized by the temple. Through this, she said that she was able to experience expansion into a new world and understand her role as a caregiver as a therapist, which she did not understand well. An important symbol of the egg in the Eastern tradition is fertility (Kalff, 2003), and the client broke the egg in a sandbox and showed the appearance of a new chick being born. As a therapist, the client was unsure and fearful of providing psychological therapy to someone, but by having the experience of being cared for through encounters with the divine religiosity manifested in her unconscious, she now looks at herself as a therapist who can take care of someone. This symbolically shows the birth of the client's new ego, and through this, the client newly recognizes herself as a therapist who cares for the suffering. This means that the client has had a divine experience in which the mental energy begins to flow again and the emotions are revived through the sandplay therapy work (Kowen, 2019).

\section{Conclusion}

The COVID-19 pandemic, which no one could predict, has had a huge impact on various fields, including psychotherapy. Because of this pandemic, people around the world are 
Journal of Symbols \& Sandplay Therapy, Vol.12 No.1.

experiencing anxiety, fear, addiction, depression, loss, and suicidal thoughts, and the need for psychological treatment is emerging more than ever. However, due to the risk of infection, the phenomenon of avoidance of face-to-face psychotherapy is emerging, and interest in new psychological treatment methods is increasing. Accordingly, the form of remote psychological treatment with video conferences is attracting attention from psychotherapists, active studies have been conducted on the therapeutic implications of this, and positive results have been reported. Typically, analytical psychology has a negative view of telepsychotherapy. However, among analytical psychotherapists, remote psychotherapy is a form of psychotherapy that can be used in the pandemic era, and it is said that meaningful relationships can be formed through it.

Psychological studies seeking to understand the pandemic era have been conducted and have been investigated by people from various theoretical backgrounds. Among them, analytical psychology provides insights into the deep inner world of the human unconscious beyond the limits of viewing and understanding these pandemic fears and anxieties from a clinical psychological perspective. Jung said that the absence of a symbolic system has a great influence on the survival of mankind in modern society, but analytic psychology contributes to the formation of a new symbolic system (Dourley, 2015). Stein (2020), who finds insights into the human psyche through symbols, describes the COVID-19 pandemic as an archetypal shadow of Umbra Mundi and explains that it came to us with death and fear. He says we have had the opportunity to incorporate the shadows.

Holy religiosity leads people on the path of individualization that is constantly being integrated into totality(Jung, 2020). Through sandplay therapy, conducted in the form of telepsychotherapy through video conferences, the client encountered the deep religion and energy of her inner world, which was symbolically represented, and had the experience of being cared for by the unconscious, and the birth of a new ego. These therapeutic results indicate that sandplay therapy is possible even through telepsychotherapy, showing that there are meaningful therapeutic results. Before helping clients find a safe and protected space, therapists must first prepare their own sacred inner space (Jang, 2020). As a school therapist, the client had the experience of preparing an inner space to help her own clients, through sandplay therapy conducted by video conference. Through this, she has discovered a new ego, and can take care 
of her clients as a therapist. Through sandplay therapy, the client was able to experience the integration of the original shadows such as anxiety, fear, and loss amplified by COVID-19.

To proceed with sandplay therapy through video conferences, the client must have all the necessary sandplay therapy tools; many clients may not have these tools. Nevertheless, this study implies that when sandplay therapy can be provided through video conferences, it has the same therapeutic effect as face-to-face sandplay therapy. The unconscious, which transcends time and space, shows clients and analysts in different spaces through images, a world of infinite symbols unfolded in a sandbox. Sandplay therapy through telepsychotherapy opens up a field of therapy in which the client can experience the symbolic world of the deep unconsciousness and the weak ego's integration with the unconscious world. This is where Umbra Mundi is swept away in the era of the COVID-19 pandemic, and sandplay therapy through video conferences invites clients into a world of infinite and sacred symbols and leads them to a place of play and change where they can experience the inner world.

\section{References}

Bradway, Kay \& Barbara McCoard. Sandplay: Silent workshop of the psyche. London Routledge, 1997.

Bekes, V., Doorn, K. A-V., Prout, T. A., \& Hoffman, L. (2020). Stretching the analytic therapists' experiences with remote therapy during COVID-19, Connecting Research and Researchers Retrieved December 12, 2020, from http://orcid.org/0000-0003-3043-5155.

Bennett, C. B., Sever, A. C., \& Yanouri, L. (2020). Ehealth to redress psychotherapy access barriers both new and old: A review of reviews and meta-analyses Journal of Psychotherapy Integration $30(2), \quad 188-207$.

Besser, A., Flett, G. L., Nepon, T., Zeigler-Hill, V. (2020). Personality cognition and adaptability to the COVID-19 pandemic Associations with loneliness distress and positive and negative mood states. International Journal of Mental Health and Addiction. Retrieved December 12, 2020, from http://doi.org/10.1007/s11469-020-00421-x

Buttell, F., Cannon C. E. B., Rose, K., \& Ferreira R. J. (2021). COVID-19 and intimate partner violence Prevalence of resilience and perceived stress during a pandemic Traumatology. Retrieved January 20, 2021, from http://dx.doi.org/10.1037//trm0000296 
Journal of Symbols \& Sandplay Therapy, Vol.12 No.1.

Carey, L. (1999). Sandplay therapy with children and families. New Jersey: Jason Aronson INC, 1999.

Casement, A. (2003). Encountering the shadow in rites of passage a Study in activation. Journal of Analytical Psychology 48, 29-46.

Daele, T. V., Karekla, M., Kassianos, A. P., Compare, A., Haddouk, L., Salgado, J., Ebert, D. D., Trebbi, G., Bernaerts, S., Assche, E. V., \& Witte, N. A. J. D. (2020). Recommendation for policy and practice of telepsychotherapy and e-mental health in Europe and beyond. Journal of Psychotherapy Integration 302), 160-173.

Douglas, S., Jensen-Doss, A., Ordorica, C., \& Comer, J. S. (2020). Strategies to enhance communication with telemental health measurement-based care (tMBC), American Psychological Association 5(2), 143-149.

Dourley, J. P. (1995). The Religious significance of Jung's psychology. The International Journal for the Psychology of Religion, 5(2), 73-89.

Dutra, C. D. C. \& Rocha, S. H. (2020). Religious support as a contribution to face the effects of social isolation in mental health during the pandemic of COVID-19, Journal of Religion and Health. 6Q1). Retrieved December 12, 2020, from http://doi.org/10.1007/s10943-020-01140-2

Eom, M. Y. (2014). Water: a symbol of potential. Journal of Symbols Therapy 5(1), 59-71.

Gallagher, M. W., Zvolensky, M. J., Long, L. J., Rogers, A. H., \& Garey, L. (2020). The impact of COVID-19 experiences and associates stress on anxiety depression and functional impairment in American adults Cognitive Therapy and Research 44, 1043-1051.

Gruber, J., Prinstein, M. J., Clark, L. A., Rottenberg, J., Abramnowitz, J. S., Albano, A. M., Aldao, A., Borelli, J. L., Chung, T., Davila, J., Forbes, E. E., Gee, D. G., Hall, G. C. N., Hallion, L. S., Hinshaw, S. P., Hofmann, S. G., Hollon, S. D., Joormann, J., Kazdin, A. E., Klein, D. N., Greca, A. M., Levenson, R. W., MacDonald III, A. W., McKay, D., McLaughlin, K. A., Mendle, J., Miller, A. B., Neblett, E. W., Nock, M., Olatunji, B. O., Persons, J. B., Rozek, D. C., Schleider, J. L., Slavich, G. M., Teachman, B. A., Vine, V., \& Weinstock, L. M. (2020). Mental health and clinical psychological science in the time of COVID-19: Challenges opportunities and a call to action. American Psychological Association. Retrieved December 12, 2020, from http://dx.doi.org/10.1037/amp0000707

Henssler, J., Stock, F., Bohemen, J. V., Walter, H., Heinz, A., \& Brandt, L. (2020). Mental health effects of infection containment strategies: Quarantine and isolation-a systematic review and meta-analysis, European Archives of Psychiatry and Clinical Neuroscience. Retrieved December 14, 2020, from https://doi.org/10.1007/s00406-020-0116-x.

Hillman, J. (1988). Archetypal psychology A brief account (3rd ed.). Texas: Spring Publication. 
Hwang, H. R. (2020). A research on the tuttle's symbolic ambivalence and its role as a spiritual guide for individuation entrance, Journal of Symbols \& Sandplay Therapy, 11(1), 99-145.

Inchausti, F., MacBeth, A., Hasson-Ohayon, I., \& Dimaggio, G. (2020). Telepsychotherapy in the age of COVID-19: A commentary Journal of Psychotherapy Integration, 30(2), 394-405.

Jang, M., Stein., M., Ramos, D., Ravitz, L., \& Jung, H. (2020, December). The connection between psyche and material. In M. Jang(Chair), Sandplay therapy of pandemic era. Symposium conducted at the academic conference of Korean Society of Sandplay Therapy, Seoul, Republic of Korea.

Jobes, D. A., Crumlish, J, A., \& Evans, A. D. (2020). The COVID-19 pandemic and treating suicidal risk: The telepsychotherapy use of CAMS, American Psychological Association, 30(2), 226-237.

Johnson, S., Dalton-Locke, C., Juan, N. V. S., Foye, U., Oram, S., Papamichail, A., Landau, S., Olive, R. R., Jeynes, T., Shah, P., Rains, L. S., Lloyd- Evans, B., Carr, S., Killaspy, H., Gillard, S., \& Simpson, A. (2020). Impact on mental health care and health service users of the COVID-19 pandemic: A mixed methods survey of UK mental health care staff, Social Psychiatry and Psychiatric Epidemiology. Retrieved December 10, 2020, from https://doi.org/10.1007/s00127-020-01917-4

Jung, B. H. (2020). Jung and the importance of religious experience: The therapeutic effect of inner experience through sandplay therapy, Journal of Symbols Therapy, 11(1), 1-38.

Jung, C. G.(1966). Psychology and religion. New York: the Vail-Ballou Press.

Kalff, D. M. (2003). Sandplay: A psychotherapeutic approach to the psyche. California: Temenos Press.

Kim, N. K. (2020). Symbolism of snake that stimulate restoration and transformation of visceral vitality, Journal of Symbols Therapy, 11(1), 191-230.

Kowen, M. R. (2019). A symbol of healing with feminine vitality: The willow, Journal of Symbols Therapy, 10(1), 37-63.

Kujawa, A., Green, H., Compas, B. E., Dickey, L., \& Pegg, S. (2020). Exposure to COVID-19 pandemic stress: Association with depression and anxiety in emerging adults in the United States, Depress Anxiety, 37, 1280-1288.

Madigan, S., Racine, N., Cooke J. E., \& Korczak, D. J. (2020). COVID-19 and telemental health: Benefits, challenges, and future directions, Canadian Psychology, Retrieved December 10, 2020, from http://dx.doi.org/10.1037/cap0000259

Moore, N. (1984). The left hand of darkness: Aspects of the shadow and individuation, Journal of Analytical Psychology, 29, 255-275. 
Journal of Symbols \& Sandplay Therapy, Vol.12 No.1.

Perrin, P. B., Rybarczyk, B. D., Pierce B. S., Jones, H. A., Shaffer, C., \& Islan, L. (2020). Rapid telepsychology deployment during the COVID-19 pandemic: A special issue commentary and lessons from primary care psychology training, J. Clin. Psychol, 76, 1173-1185.

Pierce, B. S., Perrin, P. B., Tyler, C. M., McKee, G. B., \& Watson, J. D. (2021). The COVID-19 telepsychology revolution: A national study of pandemic- based changes in U.S. mental care delivery, American Psychological Association, 76(1), 14-25.

Ren, X., Huang, W., Pan, H., Huang, T., Wang, X., Ma, Y. (2020). Mental health during the COVID-19 outbreak in China: A meta-analysis, Psychiatric Quarterly, 91, 1033-1045.

Rosen C. S., Glassman, L. H., \& Morland, L. A. (2020). Telepsychotherapy during pandemic: A traumatic stress perspective, American Psychological Association, 3022), 174-187.

Shah, S. M. A., Mohammad, D., Qureshi, F. H. M., Abbas, Z. M., \& Alleem, S. (2020). Prevalence, psychological responses and associated correlates of depression, anxiety and stress in a global population, during the coronavirus disease(COVID-19) pandemic, Community Mental Health Journal, 57, 101-110.

Shin, Y. J. and Lee, J. Y. (2020). South Korea's proactive approach to the COVID-19 global crisis, American Psychological Association, 12(5), 475-477.

Shigemura J. \& Kurosawa, M. (2020). Mental health impact of the COVID-19 pandemic in Japan, American Psychological association, 12(5), 478-479.

Shigemoto, Y. (2021). Exploring state-level variabilities between perceived community resilience and posttruamatic stress symptoms during the COVID-19 pandemic: Multilevel modeling approach, Traumatology, Retrieved February 20, 2021 from https://psycnet.apa.org/record/2021-01173-001

Stein, M. (2020, May 11). A world shadow: COVID 19. Retrieved February 20, 2021 from https://junginla.org/mstein/

Stein, M. (2020, May 8). Interview with Murray Stein for pacifica graduate institute. Retrieved February 20, 2021 from https://www.pacificapost.com/interview-with-murray-stein

Twenge, J. M., \& Joiner, T. E. (2020). Mental distress among U.S. adults during the COID-19 pandemic, J. Clin. Psychol, 76, 2170-2182.

Wardell. J. D., Kempe, T., Rapinda, K. K., Single, A., Beilevicius, E., Frohich, J. R., Hendershot, C. S., \& Keough, M. T. (2020). Drinking to cope during COVID-19 pandemic: The Role of external and internal factors in coping motive pathways to alcohol use, solitary drinkig, and alcohol problems, Alcoholism Clinical \& Experimental Research, 44(10). Retrieved December 20, 2020 from https://psyarxiv.com/8vfp9/

Watts, S., Marchand, A., Bouchard, S., Gosselin, P., Langlois, F., Belleville, G., Douglas, M. J. 
(2020). Telepsychotherapy for generalized anxiety disorder: Impact on the working alliance, American Psychological Association, 302), 208-225.

Weinrib, E. L. (2004). Images of the self: The sandplay therapy process. California: Temnos Press

World Health Organization. (2021). Coronavirus disease (COVID-10) pandemic. Retrieved from https://www.who.int/emergencies/diseases/novel-2019.

Xin, R., Wanli, H., Huiping, P., Tingting, H., Zinwei, W., \& Yongchun M. (2020) Mental health during the COVID-19 outbreak in China: A meta-analysis. Psychiatric Quarterl, 91, 1033-1045.

Yildirim, M., Kizilgecit, M., Secer, I., Karabulut, F., Angin, Y., Dagci, A., Vural, M. E., Bayram, N. N., \& Cinici, M. (2020). Meaning in life, religious coping, and loneliness during the Coronavirus health crisis in Turkey, Journal of Religion and Health. Retrieved December 15, 2020 from https://link.springer.com/article/10.1007/s10943-020-01173-7

Yue, J., Zang, X., Le, Y., \& An, Y. (2020). Anxiety, depression and PTSD among children and their parent during 2019 novel coronavirus disease (COVID-19) outbreak in China, Current Psychology. Retrieved December 20, 2020 from https://link.springer.com/article/10.1007\%2Fs12144-020-01191-4

Zvolensky, M. J., Garey, L., Rogers, A. H., Schmidt, N. B., Vujanovic, A. A., Storch, E. A., Buckner, J. D., Paulus, D. J., Alfano, C., Smits, J. A. J., \& O’Cleirigh, C. (2020). Psychological, addictive, and health behavior implications of the COVID-19 pandemic, Behaviour Research and Therapy. Retrieved December 20, 2020 from www.elsevier.com/locate/brat 